\title{
Bernard Bourdin, Le christianisme et la question du théologico-politique
}

Paris, Éditions du Cerf, coll. « Philosophie », 2015, 558 p., Préface de Philippe Capelle-Dupont.

\section{Vincent Petit}

\section{(2) OpenEdition}

\section{Journals}

Édition électronique

URL : http://journals.openedition.org/assr/28191

DOI : 10.4000/assr.28191

ISSN : $1777-5825$

Éditeur

Éditions de l'EHESS

Édition imprimée

Date de publication : 31 décembre 2016

Pagination : 277

ISSN : 0335-5985

\section{Référence électronique}

Vincent Petit, «Bernard Bourdin, Le christianisme et la question du théologico-politique », Archives de sciences sociales des religions [En ligne], 176 | octobre-décembre 2016, mis en ligne le 17 juillet 2017, consulté le 24 septembre 2020. URL : http://journals.openedition.org/assr/28191 ; DOI : https:// doi.org/10.4000/assr.28191

Ce document a été généré automatiquement le 24 septembre 2020.

(c) Archives de sciences sociales des religions 


\section{Bernard Bourdin, Le christianisme et la question du théologico- politique}

Paris, Éditions du Cerf, coll. « Philosophie », 2015, 558 p., Préface de Philippe Capelle-Dupont.

\section{Vincent Petit}

\section{RÉFÉRENCE}

Bernard Bourdin, Le christianisme et la question du théologico-politique, Paris, Éditions du Cerf, coll. «Philosophie », 2015, 558 p., Préface de Philippe Capelle-Dupont

1 Cet ouvrage, issu d'une thèse de doctorat en philosophie soutenue devant l'Institut Catholique de Paris, est une véritable summa, et comme telle dense, d'une lecture parfois difficile, nourrie de nombreuses citations et mobilisant un matériau abondant qui suscite l'admiration. Une préface synthétique de Philippe Capelle-Dumont et une conclusion resserrée en facilitent toutefois l'approche. En outre, Bernard Bourdin a déjà avancé un certain nombre des analyses qu'il livre ici dans de précédentes publications, comme La genèse théologico-politique de l'État moderne. La controverse de Jacques ${ }^{\text {er }}$ d'Angleterre avec le cardinal Bellarmin paru en 2004 ou La Médiation chrétienne. Les jeux de Léviathan en 2009.

2 L'ouvrage se décompose en trois parties d'inégale longueur. La première consiste en une vaste fresque, qui va de Thomas d'Aquin et Marsile de Padoue jusqu'à Marcel Gauchet, en passant par Bodin, Spinoza, Locke, Hobbes, Rousseau, Benjamin Constant, Hegel, Hannah Arendt, Leo Strauss et Blumenberg, centrée sur deux problèmes : la médiation chrétienne aux prises avec l'émergence de la sphère publique politique (qu'elle ait pour nom temporel, État, liberté, démocratie) et l'insatisfaction intrinsèque que procure la Modernité séculière qui n'a d'autre horizon qu'elle-même. La deuxième partie qui sert de pivot à l'ensemble de la démonstration - sa «fonction » est centrale 
reconnaît l'auteur (p. 525) - est consacrée à Carl Schmitt (et accessoirement à la polémique Schmitt-Peterson), ou plutôt à l'œuvre du célèbre juriste rhénan de part et d'autre de 1933. Enfin, la troisième partie, de moitié plus réduite que les deux premières, mais de loin la plus originale, met en miroir, pour utiliser un terme schmittien, judaïsme et christianisme à travers L'Étoile de la rédemption de Rosenzweig.

Il est imprudent, voire impossible, de résumer un tel livre. Le mieux est de reprendre les trois thèses explicitées par l'auteur en conclusion. La genèse de la Modernité séculière, en l'occurrence ici la démocratie libérale, n'est intelligible qu'en convoquant les catégories théologiques du christianisme. Or, celles-ci ont été reléguées hors du champ politique quand le politique s'est transformé en réfutant toute hétéronomie. Un tel processus a généré un « besoin anthropologique incompressible » de transcendance, qui est susceptible de "réinvestir à nouveaux frais des catégories théologicopolitiques»(p.515-516). La quatrième de couverture écrit plus crûment «que le problème théologico-politique que l'on pensait résolu depuis le siècle des Lumières, la Révolution française et la laïcité, revient avec force ».

Même si l'auteur revendique une "méthodologie historique " (p.515, p. 517), et s'il rend le christianisme indissociable de la temporalité historique, sa démarche avant tout intellectuelle et théorique peut dérouter le lecteur familier des historiens des idées comme Quentin Skinner (The Foundations of Modern Political Thought, 1978. Édition française : Les Fondements de la pensée politique moderne, Albin Michel, 2001) ou du droit comme Harold J. Berman (Law and Revolution: The Formation of the Western Legal Tradition, Harvard University Press, 1983, et Law and Revolution II: The Impact of the Protestant Reformations on the Western Legal Tradition, Harvard University Press, 2003. Édition française : Droit et révolution. La formation de la tradition juridique occidentale, Librairie de l'Université d'Aix-en-Provence, 2001 et Droit et révolution. L'impact des Réformes protestantes sur la tradition juridique occidentale, Fayard, 2011). L'approche textuelle qu'il privilégie l'amène en effet trop souvent à minorer le contexte historique, social et philosophique, les divergences théologiques et ecclésiologiques y compris au sein du christianisme (ce qui vaut pour le catholicisme romain ne vaut sans doute pas pour l'orthodoxie russe; ce qui vaut pour un catholicisme ultra-majoritaire ne vaut sans doute pas pour un catholicisme minoritaire en situation de concurrence confessionnelle) et les contingences propres au temps qui passe. Manque aussi une réflexion sur ce qu'est ou doit être, dans une philosophie politique chrétienne, une nation. On pourra répondre à bon droit que ce n'est pas l'objet du livre, que Bourdin est un théologien différent d'un Congar ou d'un Lubac, et que la conclusion est plus historiciste. Reste qu'au terme de cette lecture le christianisme apparaît avant tout comme une religion qui a partie liée avec le politique, au sens où elle induit des effets sur la cité des hommes, ne serait-ce qu'en en relativisant l'importance. Le dualisme chrétien, tour à tour dénoncé ou célébré en tant que matrice de l'autonomie du politique, est à la base d'une "alliance », et non d'un pacte ou d'un contrat (p.451). Il pose une fraternité qui rend dès lors instables toutes les formes de médiation : sociale, juridique, politique, et même ecclésiale. Or, c'est l'instabilité même du complexe théologico-politique qui est source de fécondité. En mettant ses pas dans ceux de JeanLuc Marion et sa critique de « la dérive violente de la rationalité » et de ceux de Marcel Gauchet qui définit un "civisme chrétien ", Bernard Bourdin prône la nécessité d'une confrontation nécessaire entre politique et théologie: "Les peuples démocratiques, 
pour redevenir civils et politiques, ont besoin de réinventer l'intelligibilité historique de leur appartenance collective » (p. 540). 